\title{
Indisciplina escolar: uma construção coletiva
}

\author{
Maria Lucia Boarini
}

\section{Resumo}

Tecer reflexões sobre a indisciplina escolar é o propósito deste texto. Partimos do princípio de que as regras de convívio social são uma prerrogativa humana e, nesse sentido, são produções coletivas cujas formas são configuradas pelo seu tempo histórico. Portanto, ainda que a indisciplina escolar seja uma expressão particular, via de regra, traduz o que ocorre no âmbito coletivo. Nessa perspectiva, entendemos que a disciplina é um exercício diário configurado pelas exigências do momento histórico e do ambiente em que ocorre. Na escola ela é, sem dúvida, o resultado do trabalho cotidiano em sala de aula. Também seu oposto, a indisciplina, é resultado de uma construção coletiva e nessa perspectiva é que deve ser analisada.

Palavras-chave: Disciplina, comportamento na sala de aula, educação.

\section{School indiscipline: a collective construction}

\begin{abstract}
This paper aims at reflecting upon school indiscipline. We begin by the principle that the social living rules are human prerogatives. In this sense, they are collective productions whose form is configured through history. Therefore, although school indiscipline is a particular expression, it usually translates what happens collectively. In this perspective, we assume that discipline is a daily habit shaped by the demands of the historical moment and the environment in which it happens. In school, discipline is undoubtedly the result of day-to-day work in the classroom as well as indiscipline, quite the opposite, is the result of a collective construction, and so it should be examined in this view.
\end{abstract}

Key words: Discipline, classroom behavior, education.

\section{Indisciplina escolar: una construcción colectiva}

\section{Resumen}

El propósito de este trabajo es presentar reflexiones sobre la indisciplina escolar. Partimos del principio de que las reglas de convivencia social son una prerrogativa humana y consecuentemente son producciones colectivas cuyas formas son configuradas por su tiempo histórico. Por lo tanto, a pesar de la indisciplina escolar ser una expresión particular, como regla, traduce lo que ocurre en ámbito colectivo. En esta perspectiva, entendemos que la disciplina es un ejercicio diario configurado por las exigencias del momento histórico y del ambiente en que ocurre. En la escuela es sin lugar a dudas el resultado del trabajo cotidiano en aula. Asimismo, su opuesto, la indisciplina, es resultado de una construcción colectiva y en esa perspectiva es que debe ser analizada.

Palabras clave: Disciplina, conducta en la sala de clase, educación. 


\section{Introdução}

\section{O cotidiano escolar}

Troca de letras, dificuldades e problemas na aprendizagem da leitura, escrita e matemática já não detêm o monopólio das queixas escolares. A desatenção e conversas paralelas dos alunos durante as aulas, o atraso na entrada e a pressa para sair da escola, agressões verbais ou físicas aos colegas e, em alguns casos, a outros envolvidos na escola são queixas muito mais frequentes do que o esperado na instituição escolar. Desde a última década, as provocações verbais, pela intensidade e forma como se apresentam, passaram a ser entendidas como violência, na medida em que intimidam, amedrontam. É o denominado bullying, que atualmente, em virtude da tecnologia, ganhou outra dimensão, diga-se de passagem, mais preocupante. Estamos nos referindo ao cyberbullying, que no espaço virtual é uma presença constante que não tem fronteiras. Não vamos aqui tratar especificamente dessa nova modalidade de comportamento, mas apenas pontuar que tais queixas, somadas a tantas outras, já ocupam um razoável espaço no repertório dos problemas educacionais. Em suma, o comportamento do aluno, adjetivado pelos educadores de indisciplinado, delineia-se, atualmente, como mais um dos terrores das escolas de ensino fundamental e médio e dá sinais, também, de que "vasculariza, de modo invisível, todo o sistema da universidade", pois, de acordo com o coordenador da Assistência Social (COSEAS) da Universidade de São Paulo, professor Waldyr Antonio Jorge (2010, p. 4), "chegamos a um grau inédito de violência física e verbal”.

\section{A indisciplina escolar não tem nacionalidade, endereço ou classe social}

Há décadas o problema da indisciplina escolar vem tomando novas e preocupantes proporções. Além disso, a discussão sobre esse assunto já ultrapassou os limites da sala de aula ou os muros da escola para alcançar a imprensa comum. Senão vejamos o conteúdo de uma reportagem veiculada em uma das revistas de maior circulação no Brasil, no ano de 1996:

Boa parte dos professores está à beira de um ataque de nervos porque não consegue controlar a bagunça que come solta dentro das salas de aula. E o que é pior: não bastassem conversinhas, os risinhos, as guerrinhas de papel, o respeito pela figura do professor passou a ser tão raro como uma nota 10 em redação (Revista Veja, 1996, p. 54).

$\mathrm{E}$, mais que isso, se os problemas de aprendizagem tinham um endereço certo, isto é, apresentavam-se mais acentuadamente ou quase exclusivamente como uma questão da escola pública, no caso da indisciplina escolar, não há especificação quanto ao caráter (público ou privado) da instituição ou classe social. Ainda nessa reportagem temos o caso, amplamente divulgado, de um conceituado colégio particular cujo aluno foi expulso por ter atirado uma cadeira de uma janela do $2^{\circ}$ andar do prédio onde funciona a escola e depois de ter recebido oito advertências por conduta inadequada. $\mathrm{E}$, dentre tantos exemplos que ultimamente a imprensa comum vem divulgando, tivemos o caso do estudante de 14 anos, aluno de uma escola da "classe média alta paulistana" que levava na mochila um revólver Rossi calibre 38 e munição de uma arma calibre 32 (Capriglione, 2009). Interessante notar que, talvez por conta do estereótipo presente no imaginário da sociedade em geral, que entende a violência como uma característica da natureza da pessoa economicamente desfavorecida, quando atos infracionais são cometidos pelos mais favorecidos, ganham repercussão publica e escandalizam. Nesses casos não é raro que, na sequência da notícia, vários especialistas sejam consultados para explicar o fato.

Enfim, fatos dessa ordem indicam que a indisciplina procede desde a universidade e escolas cuja clientela tem maior poder aquisitivo, comumente denominada classe $A$, até colégios considerados de periferia, por atenderem o segmento da sociedade com menor poder aquisitivo. Assim, o fenômeno indisciplina escolar fragiliza explicações sustentadas em diferenças de classes sociais.

Ainda na perspectiva social, pode-se pensar que essa é uma questão de países de Terceiro Mundo. Entretanto, educadores de Portugal, por exemplo, reconhecido como Primeiro Mundo, nos dão conta de que a indisciplina é um problema "generalizado" do primeiro ciclo à universidade. É isso o que afirma a professora Maria Benedita Melo, do Departamento de Educação da Faculdade de Ciências de Lisboa, embora, segundo a professora, "não há mais indisciplina". Para essa professora, o que ocorre atualmente é "mais divulgação". Para Raul Mendes, antigo professor de português e latim que lecionou durante 35 anos no município de Setúbal em Portugal, a indisciplina "está de tal forma disseminada no ensino público que muitos professores já não se queixam à Direção e convivem com a indisciplina como se fosse a norma escolar". (Fersap, 2008).

Entendemos ser desnecessário continuar elencando exemplos para dimensionar o problema. As informações anteriormente apresentadas e o dia a dia das escolas nos dão a exata medida da questão colocada: a indisciplina escolar é um fenômeno sem nacionalidade, endereço ou classe social. Diante desse quadro, há que se perguntar como pais, professores e alunos definem, explicam e propõem resolver a questão.

Se observadas com rigor, vamos constatar que as explicações e propostas de soluções apontadas por pais e professores, formal ou informalmente, via de regra, estão circunscritas à escola, à família e, vez ou outra, à sociedade como algo mais geral, abstrato. Não raro ouvimos que atualmente as crianças e jovens "não têm limites" porque "os pais são muito permissivos" ou porque a família é "desestruturada". Assim, a "desestruturação" ou "desorganização" familiar em geral aparece como responsável pelo fracasso 
escolar dos alunos ou mesmo como fonte de comportamentos violentos manifestados pela infância e juventude. Análises dessa ordem também se referem ao professor, ou seja, a indisciplina escolar ocorre porque o professor não faz da escola uma extensão do lar e daí por diante. Essas explicações, cada qual a seu modo, nos remetem ao campo da moral e, em geral, trazem também forte tintura de nostalgia. Comumente elas apóiam-se na memória de fatos isolados descontextualizados histórica e socialmente. Vamos examinar alguns desses pontos, ainda que brevemente.

\section{As explicações e as controvérsias subsequentes}

A nosso juízo, há certa confusão quando se entende como família "desestruturada" aquela que foge ao padrão composto de pai, mãe e filhos. É ainda mais confuso quando essa ideia está ligada à população desfavorecida economicamente. Outros arranjos familiares, qualquer que seja a classe social, não necessariamente são sinônimos de desestruturação familiar. $E$ isso já é reconhecido pelos órgãos internacionais, como, por exemplo, a Comissão Econômica das Nações Unidas para a Europa (United Nations Economic Commission for Europe - UNECE), que produziu o estudo Measurement of different emerging forms of families and households, aprovado em fevereiro de 2010, "como um guia de boas práticas para a investigação, pelos institutos de estatística, das novas formas de organização das famílias" (IBGE, 2010). Para a UNECE, "Os padrões de formação, dissolução e reconstituição da família tornam-se cada vez mais heterogêneos e seus limites mais ambíguos [...], o casamento tornou-se menos central na conformação da vida das pessoas [...]. As uniões consensuais aumentaram e, em alguns países, já existe o reconhecimento legal dos casais homossexuais" (IBGE, 2010). Podemos citar também a Lei Federal n. ${ }^{0} 11.340$ (2006), popularmente conhecida como Lei Maria da Penha, que em seu o Art. $5^{\circ}$, Parágrafo II, compreende a família como "a comunidade formada por indivíduos que são ou se consideram aparentados, unidos por laços naturais, por afinidade ou por vontade expressa". Em outro trecho, expressa-se que "As relações pessoais enunciadas neste artigo independem de orientação sexual" (Lei Federal n. $\left.{ }^{\circ} 11.340,2006\right)$. Vale ressaltar que outras e novas configurações da família não são um fenômeno da atualidade. Embora não explicitado, desde a época do Brasil Colônia, há registro de outros tipos de arranjos familiares, e os filhos fora do casamento eram muito comuns (Samara, 1981).

Entender que o professor não faz da escola uma extensão do lar é outro ponto que merece revisão. São funções diferentes. O professor é preparado e especializado ao longo de um período para compartilhar com o aluno a produção e sistematização do conhecimento. É o que denominamos de profissionalização, que deve ser exercida em sintonia com as políticas públicas de educação. Até nossos dias não consta que, para exercer a função materna e paterna, obrigatoriamente os interessados devem passar por aprova- ção em cursos especializados para esse fim. Cada pai/mãe educa seus filhos a sua maneira. Ainda que eventualmente o professor, sobretudo das séries iniciais, tenha que atender algum imprevisto estranho a sua formação, isso não o faz necessariamente substituto da função paterna/materna ou das funções parentais. São atribuições diferentes, embora devam caminhar para uma mesma direção.

No que tange à qualidade do ensino, não podemos perder de vista que, no Brasil, temos escolas que oferecem ensino de qualidade. É só atentar para as escolas onde estudaram as personalidades públicas que se destacaram ou se destacam no cenário nacional, inclusive em postos de comando do país, e jovens que atualmente se destacam em diferentes cenários da sociedade brasileira. Seguramente essas pessoas passaram pela escolarização e trazem marcas do ensino que receberam. O fato é que nem sempre a educação foi democrática no Brasil. Praticamente foi a partir de 1988, quando a Constituição Federal brasileira tornou universal o acesso ao Ensino Fundamental, que houve um inegável avanço ao se trazer para os bancos escolares $97,6 \%$ das crianças entre 7 e 14 anos - faixa em que se concentra a obrigatoriedade desse nível de ensino. Isso representa 27 milhões de estudantes de acordo com a Pesquisa Nacional por Amostra de Domicílios (Pnad), do Instituto Brasileiro de Geografia e Estatística, de 2007 (Silva \& Alcântara, 2009, p. 13). Embora pareça pequeno o percentual de $2,4 \%$ das crianças que ainda não tiveram acesso ao Ensino Fundamental, isso representa aproximadamente 680 mil crianças e jovens de 6 a 14 anos que permanecem fora da escola, sendo que "as mais atingidas são as oriundas de populações vulneráveis, como as negras, indígenas, quilombolas, pobres, sob risco de violência e exploração, e com deficiência. Ou seja, as desigualdades presentes na sociedade ainda têm um importante reflexo no ensino brasileiro" (Silva \& Alcântara, 2009, p. 14).

Entretanto, o novo contingente de alunos que adentrou a escola pública não pode ser traduzido como sucesso na educação escolar. Informações do Conselho de Desenvolvimento Econômico e Social/CDES (2011) indicam que, no Ensino Fundamental no Brasil, em 2009, foi constatado $23,3 \%$ de distorção idade-série, $20,6 \%$ de reprovação e $9,4 \%$ de evasão escolar. E, no período entre os 6 e os 9 anos, quando deve ocorrer à alfabetização, 22\% das crianças não são bem sucedidas. Ora, esses dados não são nada desprezíveis e, portanto, é um ponto importante a ser considerado quando se analisam os fenômenos que ocorrem no âmbito escolar.

No que se refere às brigas e conflitos entre os jovens, de fato, na atualidade, essa questão vem tomando dimensões preocupantes, sobretudo quando ocorrem acrescidas com o uso de drogas e/ou porte de armas de fogo, mas essa é outra discussão, que foge ao escopo deste texto. O que queremos destacar é que as rixas entre jovens não são algo específico de nossos dias. Ao retomar a obra de autoria de William Shakespeare intitulada Romeu e Julieta, produzida por volta de 1595, constatamos brigas entre jovens de famílias rivais. Isso não quer dizer que rixas são comportamen- 
tos próprios da adolescência, uma fase da vida com características próprias e universais, ou seja, todos que estão nessa fase, independente do tempo ou da inserção social, terão os mesmos comportamentos.

Há que se ter claro que os conflitos são prerrogativas humanas que podem ocorrer independente de faixa etária, classe social etc. Além disso, não podemos isolar esse período da vida, bem como todos os outros, de seus condicionantes históricos e sociais. Naturalizar as brigas juvenis, a formação de gangues ou entender que a depredação escolar ocorre por conta das características de subjetividade própria da adolescência, ou que "sempre foi assim" dão indícios de miopia social. Longe de naturalizar as mazelas escolares, é necessário entendê-las à luz do momento histórico e das condições sociais em que está ocorrendo.

É evidente que todo aluno "indisciplinado" ou "violento" tem seus determinantes psíquicos, pertence a uma família, independente do seu modelo de estruturação, e que a indisciplina escolar é um fenômeno que se concretiza na escola. Como corolário, qualquer explicação sobre esse assunto deve considerar esses aspectos. O que não podemos perder de vista é que a escola, a família e o aluno não existem isoladamente. Fazem parte de uma sociedade e de um período da história que não devem ser desconsiderados. Por essa razão, em nosso entender, não há como discutir essa questão sem uma leitura do que vem ocorrendo na sociedade em que a escola, a família e todos nós vivemos sem priorizar este ou aquele aspecto, mas entendê-los na articulação em que germina o comportamento em debate.

Obviamente com essa observação não estamos propondo aqui realizar profundas incursões no mundo da sociologia ou da filosofia, até porque essas são questões cuja profundidade ultrapassa os limites deste texto. Pretendemos, apenas, destacar alguns pontos que, em nosso entender, articulam-se estreitamente com a problemática da disciplina/indisciplina na escola. Senão vejamos: estudos indicam, e já é fato notório e público, que o homem contemporâneo não se interessa e não valoriza os problemas coletivos, o espaço e os bens públicos. Basta observar o pouco cuidado das pessoas em geral com tudo o que não lhes pertence particularmente, embora seja de uso coletivo. Esse tipo de pessoa, geralmente, só se interessa por seu mundo particular, íntimo e privado, o qual absorve suas atenções, seus sentimentos e, quase sempre, toda sua energia. Como afirma Costa (1996, p. 5)

[...] no cotidiano, todos tornaram-se um estorvo para todos [...]. As revoluções democrático-burguesas haviam iniciado o processo de estranhamento do outro [...], os antigos laços de lealdade, amizade e fidelidade, embora expulsos da esfera pública, encontraram abrigo na esfera privada. O "próximo" poderia voltar a ser próximo, desde que deixasse a luz de público e se tornasse um íntimo; um familiar; um cúmplice nas relações pessoais [...].

Nessa perspectiva, alguns desdobramentos tornam-se evidentes. Como afirma Matos (2010):
O padrão do raciocínio e do pensamento fica sendo o da autoconservação, da produção, do trabalho e do desemprego... quer dizer, as questões propriamente políticas ficam confundidas com as questões econômicas, e a tradição do espaço público, portanto, de um mínimo de espaço garantido de igualdade, onde todas as diferenças possam dialogar, um espaço que independa de poder aquisitivo, de religião, de raça, de preferências ideológicas... isso está tendendo a desaparecer nessa indiferenciação de uma igualdade abstrata no mercado consumidor.

Paralela a essa repressão do pensamento e ao descaso pelo bem público, ocorre, também, a indiferença pelos difíceis problemas vivenciados pela sociedade. Assim, a fome, a violência, a tragédia, a chacina, a prostituição infantil, por exemplo, "sensibilizam" apenas quando são presenciadas ou no ato da sua divulgação pela mídia. Provocam alguns espasmos de mal-estar, mas é por pouco tempo. A memória do homem contemporâneo está talhada para resolver esta questão: não registra. É a banalização do horror e a desconsideração da dignidade alheia. "No individualismo contemporâneo, a impessoalidade converteu-se em indiferença [...]. Pouco a pouco, desaprendemos a gostar de 'gente' [...]. Tudo é motivo de conflito, desconfiança, incerteza e perplexidade. Ninguém satisfaz a ninguém" (Costa, 1996, p. 5).

Em contraponto, reverencia-se o indivíduo e tudo o que a ele diz respeito. $O$ desejo e a motivação passam a ser as palavras de ordem. Esse individualismo exacerbado, todavia, não isenta o homem de seus custos:

A solidão é o estado de uma nova subjetividade coletiva (grifo nosso) e fundadora de uma vida moral. Esta consciência, alheia aos destinos do outro, tanto emerge das novas formas de produzir e viver na sociedade capitalista 'digitalinformática', como se origina da ameaça que provém dos excluídos (Genro, 1996, p. 3).

Entretanto, repercussões desse estilo de vida não tardam a aparecer. O suicídio entre jovens pode ser um desses rebatimentos ao se levar em conta que "No mundo inteiro, o suicídio está entre as cinco maiores causas de morte na faixa etária de 15 a 19 anos. Em vários países ele fica como primeira ou segunda causa de morte entre meninos e meninas nessa mesma faixa etária", informa a Organização Mundial da Saúde (2000). Em estudo realizado em algumas das principais capitais do Brasil, Souza, Minayo e Malaquias (2002):

Observaram no Brasil um crescimento de $35,3 \%$ na taxa de mortalidade por suicídio entre jovens de 15 a 24 anos em suas principais capitais. A cidade de Belo Horizonte apresentou taxa de mortalidade de 4,3 no ano de 1979 e $6,8 / 100.000$ habitantes em 1995; portanto, um crescimento de $58,1 \%$ no período estudado. 
Abasse, Oliveira, Silva e Souza (2009), em análise realizada sobre a situação de saúde do estado de Minas Gerais, constatou que houve "aumento nas taxas de mortalidade por suicídio nos jovens de 15 a 29 anos de 47,5\%, entre 2000 e 2004, sendo que, neste último ano, passou a ser o segundo grupo etário de maior risco de morte por essa causa". Estudo realizado por Waiselfisz (2011) denominado Mapa da Violência de 2011 - Jovens do Brasil, resultante da colaboração entre o Ministério da Justiça e do Instituto Sangari, conclui, dentre outras questões, que o suicídio foi a causa de mortalidade violenta que mais cresceu na década de 1998-2008. E a incidência de suicídios entre a população jovem na faixa etária de 15 a 24 anos é mais elevada no Brasil do que na maioria dos países. Esse estudo alerta ainda para o fato de que as taxas de suicídio no Brasil sempre foram relativamente baixas se comparadas aos demais países. Entretanto, essa taxa vem se elevando nos últimos anos na população jovem indígena.

Também não deve ser por acaso que alguns jovens, aparentemente sem razões para crise existencial, divirtam-se ateando fogo em uma pessoa que, por força das circunstâncias, dormia em uma das ruas da cidade de Brasília, no Distrito Federal. Quem não se lembra do emblemático caso do índio pataxó Galdino Jesus dos Santos? A defesa de seus incendiários alega que tudo não passou "de engano" fruto de uma "brincadeira", pois os jovens acreditavam que era um mendigo e queriam apenas "assustar" a pessoa que dormia ao relento (Mignone, 2001). Para desmistificar a ideia de que se trata de problemas de cidade grande, na pacata cidade interiorana de Lindoia, no Estado de São Paulo, três jovens "laçaram, bateram, arrastaram e amarraram" um morador de rua a um poste. Nos depoimentos coletados na delegacia de polícia, alegaram que "foi só uma brincadeira" (Folha de São Paulo, 2011). São exemplos da "coisificação" do outro. Constatamos assim que essa parece ser uma possibilidade dependendo da classe social em que esse outro esteja inserido.

Mas dirá o leitor: essas são questões complexas e mais amplas da sociedade, qual é a relação com a temática da indisciplina escolar?

Não há como negar a complexidade dessas questões. Contudo, insistimos em afirmar que é necessário não perder de vista que a escola, a família e todos os indivíduos envolvidos nessas instituições são partes constituintes dessa sociedade; portanto, não estão isentos dos encaminhamentos e sentimentos produzidos por essa mesma sociedade. Diante do que ocorre no interior de uma escola inserida em uma sociedade que privilegia o particular, onde o apreço pelo público esvai-se a olho nu, não é difícil constatar que o prestígio da escola, enquanto espaço público (particular ou não), e do magistério, enquanto uma função pública, esteja fragilizado nessa sociedade.

Dessa forma, quando a "falta de motivação" é apontada como uma das causas da indisciplina escolar, pode-se entender que as necessidades individuais não foram atendidas. A desobediência à norma é justificada pelo caráter íntimo de cada um. Em escola particular, geralmente, essa questão é ainda mais evidente, e a tirania do aluno que "paga a escola" é um fato. O professor deve ser capaz de "segurar" a atenção do aluno, portanto, motivá-lo. Assim, via de regra, professor competente é aquele que mantém a classe em silêncio. Nessa linha de raciocínio, há que se considerar, também, a dificuldade de alguns pais e professores para estabelecer as regras de convivência social, justificada pelo cuidado em não traumatizar a criança ou adolescente, ou não cercear suas possibilidades de crescimento psicológico. Em contrapartida, até para "salvaguardar o indivíduo", há casos em que se adota o controle extremamente rígido, beirando a repressão, como "não deixar sobrar tempo nas aulas/ não dar muita liberdade aos alunos", "não permitir a saída do aluno durante as aulas" e outras iniciativas do gênero.

Ora, quer no caso de recorrer a todos os meios para motivar e atender o desejo do aluno, quer no outro extremo em que o cerceamento da liberdade é o argumento principal para manter o aluno atento em sala de aula, o educador, tal como o aluno, parece não ter claro o significado e a razão de ser da disciplina. Esta não deve ser identificada, apenas e unicamente, com silêncio, ordem e outros comportamentos do gênero. $E$ aqui nos cabe discutir um pouco mais sobre o significado da disciplina.

Primeiro, a disciplina é imprescindível para o desenvolvimento de qualquer atividade, seja individual ou em grupo. Desenvolvida isoladamente ou em grupo, toda atividade, de qualquer natureza, exige ordem para chegar a bom termo. Não podemos permanecer em uma biblioteca lendo e assobiando. Além de prejudicar a própria atenção de quem está se comportando dessa forma, interfere na atenção dos demais usuários da biblioteca. Já na realização de um certame qualquer que seja, não se espera silêncio, quer dos jogadores que disputam o certame, quer da plateia que os assiste. A disciplina, nesse caso, é diferente para quem assiste e para quem realiza o jogo, ou seja, dos torcedores não se espera silêncio, mas que permaneçam em seus lugares, já para os jogadores, cada qual respeitando sua posição, espera-se movimento e ação. Como afirma Carvalho (1996, p. 132),

Agir disciplinadamente em um jogo de futebol, em um mosteiro ou em um laboratório requer não só ações diferentes, mas um espírito diferente até em relação às próprias regras. Em um, o silêncio pode ser fundamental e em outro, um entrave. (grifo nosso).

Nessa perspectiva, são inúmeros os exemplos que podemos citar, inclusive no ambiente escolar.

Observado sob esse prisma, o comportamento disciplinado não pode ser entendido como comportamento padronizado, rígido. Pelo contrário, a disciplina exclusivamente "regulamentadora" pode impedir a criatividade. Assim, por exemplo, "as regras do futebol não só regulamentam, mas possibilitam o jogo. As regras e proibições no trânsito não visam impedir o deslocamento de veículos, mas ajudá-los" (Carvalho, 1996, p. 132). Se, por outro lado, nenhuma norma for atendida e cada qual fizer a sua maneira, seguramente esse será o caminho mais indicado em direção ao caos. 


\section{O reverso da medalha}

Dessa forma, o caráter social do comportamento disciplinado/indisciplinado exige que, para compreendê-lo e interpretá-lo, necessariamente abdiquemos da ideia do aluno naturalmente indisciplinado. A indisciplina ou mesmo a subversão (saindo do âmbito escolar) podem ter outras conotações dependendo do período histórico que se vive. Explicando melhor: quem diria que o nosso benemérito educador Paulo Freire foi durante a vigência do regime militar no Brasil considerado subversivo? Ou, em outros termos, indisciplinado em relação às normas vigentes? Quando se indispôs com as arbitrariedades que vinham ocorrendo no Brasil a partir do golpe militar de 1964, Paulo Freire foi considerado subversivo (ou indisciplinado), o que o obrigou a se exilar, durante algum tempo, em outros países, conforme suas próprias palavras:

Não há quem faça uma releitura do mundo para compreendêlo melhor a não ser tocando na dimensão política e ideológica da vida humana [...]. E, obviamente, quando você desafia o homem e a mulher do povo para uma compreensão mais crítica de seu próprio mundo e da injustiça é que você desperta a necessidade de lutar [...]. E foi exatamente por isso que fui preso, expulso do país, e vivi no exílio 16 anos, fora do Brasil [...] (Freire, 1994, p. 14).

Esse é apenas um, dentre inúmeros exemplos do abominável período da ultima ditadura militar (1964-1984) da história do Brasil. Assim, recuperando alguns exemplos de pessoas historicamente consideradas rebeldes, subversivas, portanto, indisciplinadas, vamos dando conta de que, em determinadas situações, comportamentos julgados e punidos por transgredir as normas estabelecidas davam, ao contrário do que se supunha, sinais de autonomia, de não aceitação do arbítrio, do inconformismo ao cerceamento à liberdade de ideias e de expressão. Enfim, são as normas estabelecidas pela família, pela escola ou pela sociedade em geral, em determinados momentos históricos, que atribuem o significado do comportamento disciplinado ou indisciplinado. Reiterando nossas afirmações anteriores, o educador brasileiro Paulo Freire, reconhecido internacionalmente, foi considerado um subversivo, portanto indisciplinado, porque transgrediu as normas vigentes nos anos de chumbo (19641984) que aconteceram em território brasileiro.

Nessa linha de raciocínio, há que se pensar, também, que o comportamento indisciplinado pode estar revelando os conflitos velados da instituição e, mais que isso, pode estar indicando a insatisfação com uma escola, que dia a dia torna-se cada vez mais anacrônica e incompetente para cumprir sua função social. É uma escola que aumentou em número, mas, até nossos dias, no Brasil não garantiu a qualidade do ensino. Portanto, a considerar os resultados indicados anteriormente, a ineficiência é uma das marcas da escola na atualidade. Grosso modo, arriscamos afirmar que essa indisciplina generalizada que se observa nas escolas pode estar indicando que "a escola tal como existe hoje já tem seus dias contados", como afirma Gandolfo (1993, p. 21). Por um lado, um dos motivos, provavelmente, é o fato de que a escola ainda não adentrou na era digital, sobretudo a maioria das escolas públicas. E entrar na era digital não significa apenas capacitar professores, comprar laptops, montar enormes laboratórios de informática, porém deixar o aluno usar apenas uma vez por semana e, geralmente, sem conexão enquanto as providências estão sendo tomadas para censurar determinados acessos. A escola não pode se manter distante das inúmeras possibilidades presentes na era digital. Entrar na era digital é reconhecer que vivemos em um mundo cada vez mais globalizado e, de uma forma ou de outra, o pensamento contemporâneo já vem sendo produzido com recursos das novas tecnologias. Portanto, introduzir de fato a tecnologia digital na escola é "falar a mesma língua" dos estudantes. A utilização da informática na transmissão e construção do conhecimento não significa condenar à extinção a instituição escolar e o professor ou fazer a apologia da tecnologia e suas derivações. Até porque as novas tecnologias criadas pela sociedade não fazem desaparecer, num piscar de olhos, formas anteriores de expressão. Com essas considerações, estamos apenas destacando a necessidade de a escola acompanhar o seu tempo histórico.

Por outro lado, em geral ainda se mantém a didática que considera o professor como o único detentor do saber em sala de aula. O aluno deve manter-se, horas a fio, calado e atento. O professor vai se habituando a trabalhar com os "limites do não pode", ao invés de privilegiar os "limites da possibilidade", não levando em conta que o objetivo do trabalho pedagógico é "suprimir a figura do aluno enquanto aluno, isto é, o trabalho pedagógico se efetua para fazer com que a figura do estudante desapareça" (Chauí, 1980, p. 39).

Temos que reconhecer que no Brasil a democratização do acesso ao Ensino Fundamental e Médio é um fato incontestável. Todavia a qualidade de ensino mantém-se distante da democratização do saber. A defasagem do ensino no período inicial e médio da escolarização, sobretudo na rede pública de ensino, parece esvanecer seu significado formativo. No esvaziamento do sentido político-formativo, outras promessas passam a ocupar a finalidade da educação escolar, por exemplo, ascensão econômica e social, ingresso nas universidades públicas etc. Entretanto, até mesmo essas promessas não têm sido cumpridas pela escola. Como exemplo, temos a institucionalização dos cursinhos pré-vestibulares, que comprova que as escolas não garantem o ingresso nas concorridas universidades públicas. Recentemente estamos assistindo a discussão do controverso sistema de cotas para ingresso no ensino superior. Algumas universidades brasileiras já adotaram o sistema de cotas para egressos da escola pública. Quanto a exemplos bem sucedidos de ascensão econômica e social, que sequer mencionam a educação formal, ganham visibilidade na mídia, chegando a ser assunto de capa de revista de grande circulação nacional (Rangel, Carvalho, \& Diniz, 2011).

Diante desse quadro, não é difícil entender a razão de a escola deixar de ser motivo de júbilo ou de felicidade 
para a juventude, como aponta o estudo de Camargo, Abaid e Giacomoni (2011). Tendo como objetivo compreender o conceito de felicidade, esses autores realizaram uma pesquisa junto a 95 adolescentes, de ambos os sexos, na faixa etária entre 12 e 20 anos, estudantes de escolas públicas do ensino fundamental. Dentre os resultados, chama atenção o fato de apenas $2 \%$ dessa população associar a escola à noção de felicidade.

Nessa sintonia, assistimos ao grande desprestígio do estudo e da instrução, como é possível observar na canção rap do compositor Gabriel Pensador: “(...) Decorei, copiei, memorizei, mas não entendi / Decoreba: esse é o método de ensino / Eles me tratam como ameba e assim eu num raciocínio / Não aprendo as causas e consequências, só decoro os fatos / Desse jeito até história fica chata (...)"

Desconsiderando a dinâmica sócio-historica, em geral, a escola recebe e trata o aluno como se ele estivesse ingressando em "outro mundo". E aqui podemos observar, no mínimo, duas situações.

Uma dessas situações é bem definida por Passos (1996, p. 123):

Entrar para a escola significa romper com as formas de mover-se, de falar, de estar, cultivadas no espaço cotidiano da vida dos alunos fora da escola. É um espaço organizado para que todos os alunos sejam iguais, para que todos aprendam do mesmo jeito, no mesmo ritmo.

Vivendo em uma época de exaltação da diversidade, da livre expressão, enfim do incentivo ao fazer democrático, os encaminhamentos da escola ainda se pautam nas leis da natureza, isto é, as normas disciplinares são interpretadas como naturalmente universais e "eternas". Nenhum comportamento que transgrida o instituído é avaliado como uma possível indicação de autonomia ou de necessidade de revisão das práticas vigentes. A dúvida da legitimidade do instituído é percebida e interpretada com intolerância. O indivíduo particular é quase sempre responsabilizado pelas tensões e conflitos existentes. E, nesse ponto, vai se delineando o grande impasse criado por essa forma de avaliar e encaminhar os cotidianos conflitos escolares. Vejamos como ocorre esse impasse.

Ao partir do princípio de que o aluno não obedece às regras escolares porque é "da sua natureza" ou da "natureza da sua família" ser indisciplinado, estamos tratando com uma característica inata e, nesse sentido, imutável. Então, como fazer que esse aluno siga normas que também "sempre foram assim" e com as quais ele não concorda? Ora, ao atribuir a fatores inatos a causa da geração dos conflitos ou do comportamento indisciplinado do aluno, isentando-nos de qualquer responsabilidade, não é difícil concluir que ficamos impossibilitados de promover quaisquer mudanças. Nesse caso, se "é assim" e "sempre foi assim", parece que não há nada a fazer. Então só nos resta a contemplação.

A outra situação é, aparentemente, oposta à exigência de manter o aluno com comportamento "engessado". Nesse sentido, o aluno deve ser respeitado em sua esponta- neidade, sua criatividade, deixando-o produzir em seu ritmo natural. Essa questão nos faz lembrar a instigante reflexão de Klein (1995), que pontua o fato de que somos seres históricos. Contudo, isso não significa que somos naturalmente humanos. A deixar por conta da espontaneidade da condição humana, ainda não teríamos nos "distanciado da vida simiesca". A produção do humano "é uma árdua e penosa tarefa: ela supõe uma luta ingente contra tudo o que há de natural e espontâneo no indivíduo. Ela supõe o lento, difícil e doloroso aprendizado da forma civilizada de ser" (Klein, 1995).

ENFIM...

Ao reconhecer que a disciplina ou indisciplina escolar é uma prerrogativa humana e, nesse sentido, é um fenômeno complexo e incerto, não será difícil entender que nenhum comportamento social resulta de somatórias, ou de qualquer outra operação matemática, de aspectos isolados. O comportamento humano não é algo que se explique pelos pressupostos teóricos de "causa e efeito", pois o indivíduo não é passivo na forma de perceber e interpretar o mundo. Nessa perspectiva, não cabe a interpretação ligeira de que o comportamento indisciplinado é resultante unicamente de características subjetivas de um aluno em particular ou que a indisciplina que, em geral, se observa na escola é resultante da qualidade do ensino, das famílias que não impõem limites etc.

A resistência, a não aceitação do instituído ou pelo menos a sua possibilidade, o contraditório, enfim, as tensões sociais são elementos dinamizadores das conquistas e avanços da sociedade. Estar aberto a essas questões é uma tarefa árdua, sem dúvida. Porém é uma tarefa necessária de todos nós seres mortais. Tarefa essa que não pressupõe um final, mas deve ser realizada continuamente.

A disciplina e a indisciplina não são categorias lineares, estáticas e unidirecionais. Não são exclusivamente reações comportamentais que ocorrem mecanicamente por índole de um aluno em particular. O comportamento indisciplinado pode estar dando sinais de que insatisfações estão sendo produzidas no âmbito da instituição escolar ainda que sejam manifestações individuais. A promoção da disciplina ou o controle da indisciplina dos alunos não estão escritos na literatura pedagógica ou em qualquer outra, nem recebemos, junto com o diploma de conclusão de curso, fórmulas para manter a disciplina ou evitar a indisciplina. A disciplina é um exercício que se faz necessário em qualquer situação social ou não. No caso do ambiente escolar, a disciplina é um exercício diário que ocorre no cotidiano da sala de aula. Deve ser construída e administrada no dia a dia por todos os envolvidos na educação. Esse exercício não é um problema para nós educadores. Esse exercício é um compromisso e desafio e faz parte do nosso trabalho.

\section{Referências}

Abasse, M. L. F., Oliveira, R. C., Silva, T. C., \& Souza, E. R. de. (2009). Análise epidemiológica da morbimortalidade por suicídio entre 
adolescentes em Minas Gerais, Brasil. Ciênc. saúde coletiva, 14(2), 407-416.

Camargo, S. P. H., Aabaid, J. L. W., \& Giacomoni, C. H. (2011). Do que eles precisam para serem felizes? A felicidade na visão de adolescentes. Psicologia Escolar e Educacional, 15(2), 241-250.

Capriglione, L. (2009, 25 de março). Aluno leva revólver à sala de aula e cria dilema em colégio. Folha de São Paulo. Recuperado: 25 jun. 2012. Disponível: http://www1.folha.uol.com.br/fsp/cotidian/ ff2503200901.htm

Carvalho, J. S. F. (1996). Os sentidos da (in)disciplina: regras e métodos como práticas sociais. Em J. G. Aquino (Org.), Indisciplina na escola/Alternativas teóricas e práticas (pp. 129-138). São Paulo: Summus.

Chauí, M. de S. (1980). Ideologia e educação. São Paulo: Cedes/ Cortez.

Conselho de Desenvolvimento Econômico e Social. (2011). As desigualdades na escolarização no Brasil. Relatório de observação $n^{\circ}$ 4. Brasília, DF. Recuperado: 11 jan. 2012. Disponível: http://cenpec.org.br/biblioteca/educacao/estudos-epesquisas/as-desigualdades-na-escolarizacao-no-brasil-relatoriode-observacao-n-4

Costa, J. F. (1996, setembro). A devoração da esperança no próximo. Folha de S. Paulo. Caderno Mais!, p.8.

Fersap. (2008). Indisciplina é realidade antiga, agora mais divulgada. (2008). Recuperado: 12 jan. 2012. Disponível: http://www.fersap. $\mathrm{pt} /$ fersap/modules.php?name=News\&file=print\&sid=744

Folha de São Paulo. (2011, 3 de fevereiro). Agressores de morador de rua dizem que "foi só uma brincadeira". Recuperado: 25 jun. 2012. Disponível: http://www1.folha.uol.com.br/fsp/cotidian/ ff0302201110.htm

Freire, P. (1994, maio). Entrevista. Jornal Muito Mais, pp. 14-15.

Gandolfo, R. (1993, 6 de junho). A escola tem seus dias contados. Folha de S.Paulo - World Media/suplemento especial, p. 21.

Genro, T. (1996, abril). Entre a solidão e a solidariedade. Folha de S.Paulo, Caderno Mais!, p. 3.

IBGE. (2010). Síntese dos indicadores sociais. Recuperado: 10 jan. 2012. Disponível: http://www.ibge.gov.br/home/ estatistica/populacao/condicaodevida/indicadoresminimos/ sinteseindicsociais2010/SIS_2010.pdf.

Jorge, W. A. (2010, 19 de novembro). Destaques. Boletim editado pela assessoria de imprensa da reitoria. Recuperado: 9 jan. 2012.
Disponível: $\quad$ http://www.usp.br/imprensa/wp-content/uploads/ Destaque-13.pdf

Klein, L. R. (1995). O professor decreta o fim da escola. Intermeio, 1(2), 20-25.

Lei Federal n. ${ }^{\circ} 11.340$, de 7 de agosto de 2006. (2006). Cria mecanismo para coibir a violência contra a mulher. Diário Oficial da União. Brasília: Presidência da República. Recuperado: 25 jan. 2012. Disponível: http://www.planalto.gov.br/ccivil_03/_ato20042006/2006/lei//11340.htm

Matos, O. (2010). Entrevista com a filósofa Olgária Matos. Recuperado: 11 jan. 2012. Disponível: http://www.filosofia.com.br/ vi_entr.php?id=25.

Mignone, R. (2001). Defesa de acusados da morte de Galdino mantém tese de "brincadeira". Folha de São Paulo. Recuperado: 09 nov. 2001. Disponível: http://www1.folha.uol.com.br/folha/ cotidiano/ult95u40272.shtml 09/11/2001

Organização mundial da saúde. Departamento de saúde mental. (2000). Prevenção do suicídio: Manual para Professores e Educadores. Transtornos mentais e comportamentais. Recuperado: 12 jan. 2012. Disponível: http://www.who.int/mental_ health/prevention/suicide/en/suicideprev_educ_port.pdf

Passos, L. F. (1996). A indisciplina e o cotidiano escolar: novas abordagens, novos significados. Em J. G. M. Aquino (Org.), Indisciplina na escola/Alternativas teóricas e práticas. São Paulo: Summus.

Rangel, C., Carvalho, J., \& Diniz, L. (2012, 18 de janeiro). Eu quero ser EIKE. Revista Veja, pp. 79-89.

Revista Veja. (1996, maio). Unidos na bagunça. 29(22), p.54.

Samara, E. M. (1981). Casamento e papéis familiares em São Paulo no séc. XIX. Cadernos de Pesquisa, 37, 17-25.

Silva, M. S., \& Alcântara, P. I. (Orgs.). (2009). Situação da Infância e da Adolescência Brasileira 2009. O Direito de Aprender: Potencializar avanços e reduzir desigualdades. Brasília, DF: UNICEF. Recuperado: 25 jan. 2012. Disponível: http://www.unicef. org/brazil/pt/siab_capitulos.pdf.

Souza, E. R. de, Minayo, M. C. de S., \& Malaquias, J. V. (2002). Suicídio de jovens nas principais capitais do brasil. Cadernos de Saúde Pública, 18(3), 673-683.

Waiselfisz, J. J. (2011). Mapa da violência 2011: os jovens no Brasil. Recuperado: 25 jan. 2012. Disponível: http://www.sangari.com/ mapadaviolencia/pdf2011/MapaViolencia2011.pdf 
Recebido em: 30/01/2012

Reformulado em: 02/07/2012

Aprovado em: 03/09/2012

\section{Sobre a autora}

Maria Lucia Boarini (mlboarini@uol.com.br)

Doutora em Psicologia. Docente do Programa de Pós-Graduação de Psicologia da Universidade Estadual de Maringá, PR.

Endereço: Departamento de Psicologia, Universidade Estadual de Maringá, Av. Colombo, 5790, 87.020-900, Maringá, PR.

Versão revisada e ampliada do texto publicado em Apontamentos (1998, janeiro), número 69.

Indisciplina escolar: uma construção coletiva * Maria Lucia Boarini 
